\title{
Various cross-linking methods inhibit the collagenase I degradation of rabbit scleral tissue
}

Konstantin Krasselt ${ }^{1}$, Cornelius Frommelt ${ }^{1}$, Robert Brunner ${ }^{2}$, Franziska Georgia Rauscher ${ }^{3}$, Mike Francke ${ }^{1,3^{*}}$ (D) and Nicole Körber ${ }^{1}$

\begin{abstract}
Background: Collagen cross-linking of the sclera is a promising approach to strengthen scleral rigidity and thus to inhibit eye growth in progressive myopia. Additionally, cross-linking might inhibit degrading processes in idiopathic melting or in ocular inflammatory diseases of the sclera. Different cross-linking treatments were tested to increase resistance to enzymatic degradation of the rabbit sclera.

Methods: Scleral patches from rabbit eyes were cross-linked using paraformaldehyde, glutaraldehyde or riboflavin combined with UV-A-light or with blue light. The patches were incubated with collagenase I (MMP1) for various durations up to $24 \mathrm{~h}$ to elucidate differences in scleral resistance to enzymatic degradation. Degraded protein components in the supernatant were detected and quantified using measurements of Fluoraldehyde oPhthaldialdehyde (OPA) fluorescence.
\end{abstract}

Results: All cross-linking methods reduced the enzymatic degradation of rabbit scleral tissue by MMP1. Incubation with glutaraldehyde (1\%) and paraformaldehyde (4\%) caused nearly a complete inhibition of enzymatic degradation (down to $7 \% \pm 2.8$ of digested protein compared to control). Cross-linking with riboflavin/UV-A-light reduced the degradation by MMP1 to $62 \% \pm 12.7$ after $24 \mathrm{~h}$. Cross-linking with riboflavin/blue light reduced the degradation by MMP1 to $77 \% \pm 13.5$ after $24 \mathrm{~h}$. No significant differences could be detected comparing different light intensities, light exposure times or riboflavin concentrations.

Conclusions: The application of all cross-linking methods increased the resistance of rabbit scleral tissue to MMP1degradation. Especially, gentle cross-linking with riboflavin and UV-A or blue light might be a clinical approach in future.

Keywords: Scleral cross-linking, Rabbit sclera, Glutaraldehyde, Paraformaldehyde, Riboflavin/UV-A-light, Riboflavin/blue light

\footnotetext{
* Correspondence: M.Francke08@gmail.com

'Paul-Flechsig-Institute of Brain Research, Leipzig University, Liebigstraße 19, 04103 Leipzig, Germany

${ }^{3}$ Institute for Medical Informatics, Statistics and Epidemiology (IMISE), Leipzig University, Härtelstraße 16-18, 04107 Leipzig, Germany

Full list of author information is available at the end of the article
}

(c) The Author(s). 2020 Open Access This article is licensed under a Creative Commons Attribution 4.0 International License, which permits use, sharing, adaptation, distribution and reproduction in any medium or format, as long as you give appropriate credit to the original author(s) and the source, provide a link to the Creative Commons licence, and indicate if changes were made. The images or other third party material in this article are included in the article's Creative Commons licence, unless indicated otherwise in a credit line to the material. If material is not included in the article's Creative Commons licence and your intended use is not permitted by statutory regulation or exceeds the permitted use, you will need to obtain permission directly from the copyright holder. To view a copy of this licence, visit http://creativecommons.org/licenses/by/4.0/ The Creative Commons Public Domain Dedication waiver (http://creativecommons.org/publicdomain/zero/1.0/) applies to the data made available in this article, unless otherwise stated in a credit line to the data. 


\section{Background}

Cross-linking of the sclera is a promising approach to strengthen the scleral rigidity to inhibit eye growth in progressive myopia [1, 2]. The suggested beneficial effect of scleral cross-linking (SXL) treatment is the proposed reduction of the axial length elongation of highly myopic eyes to prevent pathological myopia. The risk of pathological outcomes such as chorio-retinal degeneration, retinal tears, and detachments might be minimized [3-5]. Different treatments using chemical cross-linkers or photosensitizers in combination with light of different wavelengths are object of various studies [6-8]. Crosslinking with riboflavin and UV-A or blue light increases the scleral biomechanical rigidity in a dose-dependent manner $[1,9]$. Animal studies show an inhibitory effect on eye growth in rabbit $[6,7,10]$. There are differences in efficacy to strengthen the biomechanical stiffness of collagenous tissue by different cross-linkers, which were shown by stress-strain material tests of porcine corneas. According to Spoerl \& Seiler [11], Karnovsky's solution and glutaraldehyde are the most effective cross-linkers followed by riboflavin/UV-A-light, methylglyoxal, glyceraldehyde, riboflavin/blue light and others. The most ineffective cross-linkers are glucose and short-wave UV-A-light (265 $\mathrm{nm})$ [11].

These findings led to the idea of treating corneal melting diseases due to collagenosis like rheumatoid arthritis [12]. Enzymes like collagenases and other matrix metalloproteinases play a key role in the pathogenesis of this kind of diseases by weakening the collagenous stroma and thus lead to thinning and deformation of the tissue structure $[13,14]$. Therefore, the effect of cross-linking on the resistance to enzymatic degradation was tested by Spoerl, Wollensak and Seiler at the porcine cornea [12]. The tissue was cross-linked by riboflavin and $3 \mathrm{~mW} / \mathrm{cm}^{2}$ UV-A-light (370 nm, $30 \mathrm{~min}$ ) and degraded with pepsin, trypsin and collagenase. Total enzymatic degradation of the cornea took at least twice the time of untreated control corneas.

Variations in genes coding for metalloproteinases were detected in people being affected by myopia [15-17]. In pathological myopia, the biomechanical weakening of the sclera leads to a disproportion of the optical apparatus and an elongation of the eye globe accompanied with severe pathological outcomes $[3,4,18]$. The crucial role of active collagen remodeling in the development and recovery of myopia in tree shrew was proofed by McBrien et al. [19]. Here, the underlying mechanism is a change in metalloproteinase activity which evokes a scleral weakening in several animal models with induced myopia [20-22].

The obvious consideration is to strengthen the connective tissue fibers to prevent immoderate enzymatic degradation and thus to stop resulting thinning and deformation of the sclera. It needs to be examined if cross-linking is a suitable application to increase the resistance of scleral tissue to enzymatic degradation in myopia development and melting diseases like scleritis. Therefore, we degraded rabbit scleral tissue by collagenase I after application of different cross-linking procedures. A detection system using Fluoraldehyde oPhthaldialdehyde (OPA) reagent was established to measure the amount of cleaved protein products (mostly collagen) in the supernatant. We compared the potency of different cross-linking methods to increase the scleral resistance to enzymatic degradation.

\section{Methods}

\section{Specimen preparation}

The authors have considered all ethical aspects of the study and followed the guidelines of the Helsinki Declaration and all experiments were done in accordance with the European Communities Council Directive 86/609/ EEC and the ARVO Statement for the Use of Animals in Ophthalmic and Vision Research. Experiments were approved by the local authorities (Faculty of Medicine of the University of Leipzig). We did not perform any animal experiments. The albino rabbit eyes were directly obtained from a local abattoir and frozen at $-20^{\circ} \mathrm{C}$ without additional fluid within $2 \mathrm{~h}$ post mortem. All rabbits were at an age of 12 up to 14 weeks at the time of death. The frozen albino rabbit eyes were thawed in phosphate buffered saline (PBS, pH 7.4, Biochrom AG, Berlin, Germany). Eyes were used up to 1 year post mortem. Altered or damaged eyes were discarded. After removal of outer ocular muscle and connective tissue the eye ball was opened at the ora serrata. The cornea, lens and vitreous body were removed. The eye cup was bisected in the nasal and temporal hemisphere and cleaned from retina and choroid. $8 \mathrm{~mm}$ patches were punched out of the sclera (Fig. 1) and weighed using an accuracy weighing machine (Mettler-Toledo $\mathrm{GmbH}$, Gießen, Germany). Patch weights were $21.77 \mathrm{mg} \pm 0.6$ $(n=88)$ in average. The complete methodical procedure from the specimen preparation to the peptide detection is schematically drawn in Fig. 2.

\section{Cross-linking with glutaraldehyde and paraformaldehyde} Scleral patches were incubated in $1 \%$ glutaraldehyde or $4 \%$ paraformaldehyde in PBS for 1 or $5 \mathrm{~min}$ and then rinsed in PBS for $24 \mathrm{~h}$ for a complete clearance of the chemical cross-linkers to ensure that these substances do not interfere with the enzyme (MMP1) itself and therefore, might inhibit the activity of the enzyme directly by protein cross-linking.

\section{Cross-linking with riboflavin and UV-A/blue light}

Scleral patches were incubated in riboflavin (Vitamin B2, $0.5 \%$ or $0.1 \%$ in PBS without any Dextran admixture, 


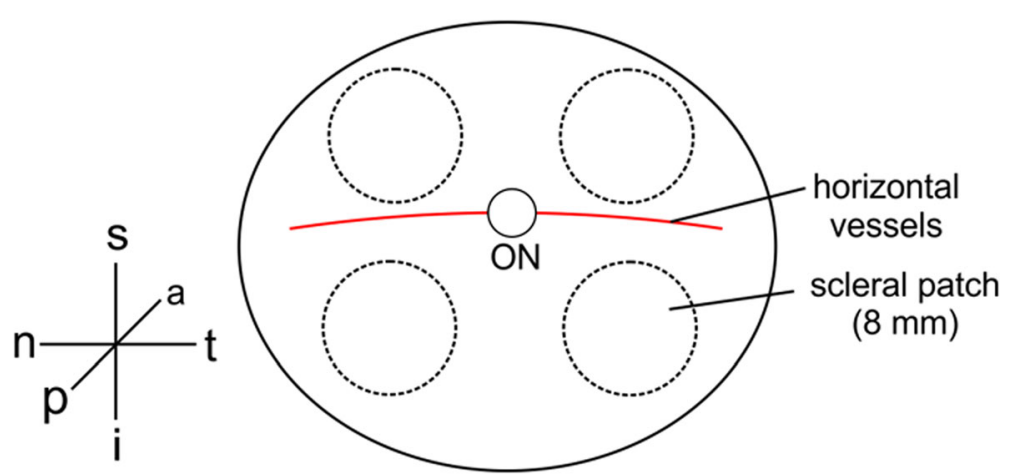

Fig. 1 Preparation of scleral patches from the rabbit eye for enzymatic degradation. After isolation of the eye, the cornea, lens, vitreous body and inner eye layers were removed and four $8 \mathrm{~mm}$ patches were punched out of the sclera. ON - optic nerve, a - anterior, i - inferior, $n-$ nasal, $p$ posterior, $\mathrm{s}$ - superior, $\mathrm{t}$ - temporal

Streuli Pharma, Uznach, Switzerland) at room temperature for $20 \mathrm{~min}$. Then, the scleral pieces were irradiated with 40 or $75 \mathrm{~mW} / \mathrm{cm}^{2}$ UV-A-light $(365 \mathrm{~nm} \pm 10$ $\mathrm{nm})$ or with 40 or $150 \mathrm{~mW} / \mathrm{cm}^{2}$ blue light $(450 \pm 25 \mathrm{~nm})$ for $10 \mathrm{~min}$ on each side. A UV-A-light source (UV-X ${ }^{\mathrm{mm}}$ 1000; IROC Innocross AG, Switzerland) was modified to provide higher light intensities. Blue light was applied using the bluephase 16i (Ivoclar Vivadent $\mathrm{GmbH}$, Ellwangen-Jagst, Germany). Riboflavin was refreshed every $5 \mathrm{~min}$ for each patch to avoid drying of the specimen and photo-bleaching of the fluorophore. The adjustment of the applied blue light intensity $\left(40\right.$ and $\left.150 \mathrm{~mW} / \mathrm{cm}^{2}\right)$ was realized by custom-built polypropylene spacing tubes in the front of the irradiation device. Different UV-A-light intensities ( 40 and $75 \mathrm{~mW} / \mathrm{cm}^{2}$ ) were adjusted in changing the distance of the scleral patches to the light source. The light intensities were measured and controlled by a power-meter device (LaserMate Q, Coherent Inc., Santa Clara, CA, USA). All samples including the controls were kept in PBS (pH 7.4, Biochrom AG, Berlin, Germany) while preparing the remaining specimens of the eye.

\section{Enzymatic degradation}

The scleral patches were incubated in $3 \mathrm{ml}$ extracellular solution composed of $136 \mathrm{mM} \mathrm{NaCl}, 3 \mathrm{mM} \mathrm{KCl}, 10 \mathrm{mM}$ HEPES and $11 \mathrm{mM}$ Glucose (Carl ROTH GmbH + Co.
KG, Karlsruhe, Germany), of $1 \mathrm{mM} \mathrm{MgCl}_{2}$ (Sigma-Aldrich, Taufkirchen, Germany and $2 \mathrm{mM} \mathrm{CaCl}_{2}$ (Merck KGaA, Darmstadt, Germany), respectively. Collagenase I was added (MMP1 from Clostridium histolyticum, Sigma-Aldrich, Taufkirchen, Germany) with a concentration of $1 \mathrm{mg} / \mathrm{ml}$ up to $24 \mathrm{~h}$ in a humid chamber on a shaker at room temperature for enzymatic degradation. Various time intervals of $1,4,8$ and $24 \mathrm{~h}$ were chosen for an enzyme kinetic analysis. At each time point $100 \mu \mathrm{l}$ of the supernatant was extracted and stored at $4{ }^{\circ} \mathrm{C}$ for peptide detection. The supernatant volume loss was considered and mathematically corrected for the peptid analysis.

\section{Peptide detection}

For analysis of degradation-products the Thermo Scientific Pierce Fluoraldehyde o-Phthaldialdehyde (OPA) Reagent (Thermo Scientific Fisher Inc., Rockford, IL, USA) was used. The chemical reacts with primary amines of amino acids, peptides and proteins to a fluorescent product that can be detected by fluorescence measurements (excitation/emission $=340 \mathrm{~nm} / 455 \mathrm{~nm}$ ). A calibration curve was determined using a standard aqueous solution of bovine serum albumin (BSA, $2 \mathrm{mg} / \mathrm{ml}$, Thermo Scientific Fisher Inc., Rockford, IL, USA), degraded bovine collagen (degraded by $1 \mathrm{mg} / \mathrm{ml} \mathrm{MMP1}$ in PBS + Glucose, 
from achilles tendon, Sigma-Aldrich, Taufkirchen, Germany) and porcine gelatine (from porcine skin, Sigma -Aldrich, Taufkirchen, Germany), respectively. All proteins were checked for their value as a fitting standard (Fig. 3). For calculation a reference value for the patches the dry weight of the scleral patches was determined by weighting the patches before and after a complete drying period with a precise analytical balance. The protein amount of the scleral patches was estimated from the total patch weight $(21.77 \mathrm{mg} \pm 0.6)$ minus $78.3 \%$ water content (own unpublished data).

Twenty $\mu$ l peptide solution / supernatant was mixed with $200 \mu$ l Fluoraldehyde OPA solution and incubated for 10 min for fluorescence measuring as recommended by the manufacturer and each sample was measured three times to identify outlier. Fluorescence was measured by an ELISA-Reader (anthos htIII, anthos Mikrosysteme GmbH, Krefeld, Germany) using the $340 \mathrm{~nm}$ excitation filter and the $450 \mathrm{~nm}$ emission filter. The relative fluorescence of the incubation medium (extracellular solution + MMP1) was set as blank and subtracted from all other values. The amount of peptide in the supernatant was calculated as percentage of the degradation products of the corresponding control sclera after $24 \mathrm{~h}$ in each experiment. The corresponding control values were incubated without any crosslinking procedure. The values were averaged and illustrated using Microsoft ${ }^{\circ}$ Office Excel 2003 (๔ 1985-2003 Microsoft Corporation). Significances were calculated with Origin Pro 2017G SR1 (๔ OriginLab Corporation) using the MannWhitney U test (unpaired, two-tailed).

\section{Results}

\section{Comparison of different peptide standards}

The quantification of a peptide amount in the supernatant extinguished from the relative fluorescence intensity requires an eligible standard protein. The comparison of three peptides showed different standard curves after incubation with Fluoraldehyde o-Phthaldialdehyde (Fig. 3). MMP1 degraded bovine collagen (blue curve, $y=0.537 x+0.0023$ ) showed stronger fluorescence intensities in comparison to bovine serum albumin (black curve, $y=0.2239 x+0.0025$ ) and porcine gelatin (red curve, $y=0.1447 x-0.0041$ ).

The supernatant peptide amount of the untreated (that means no cross-linking) rabbit sclera after a 24 h-degradation by MMP1 (black dot in Fig. 3) was measured to estimate the value of each of these standard curves. Bovine serum albumin and porcine gelatin standard curves showed similarity and can both be used to calculate the real peptide amount in the supernatant after degradation by MMP1. Because of the good solubility, easy handling and the daily use in our laboratories we used bovine serum albumin as standard for all experiments.

\section{Macroscopic appearance of the scleral patches after collagenase I degradation}

Figure 4 shows exemplary the optical appearance of scleral patches after 1,8 and $20 \mathrm{~h}$ of degradation by MMP1. An obvious decrease of the scleral patch diameter could not be observed. Over a digestion-time up to $24 \mathrm{~h}$ the tissue became transparent and the surfaces became rough. Small protein aggregates and tissue clots dissociated from the scleral patch appearing in the incubation medium. Finally, a translucent network of the former patch remained in the solution. Even after $72 \mathrm{~h}$ of incubation with collagenase I a residual network derived from scleral tissue remains and no increase of the peptide amount in the supernatant compared to 24 $\mathrm{h}$ incubation could be detected.

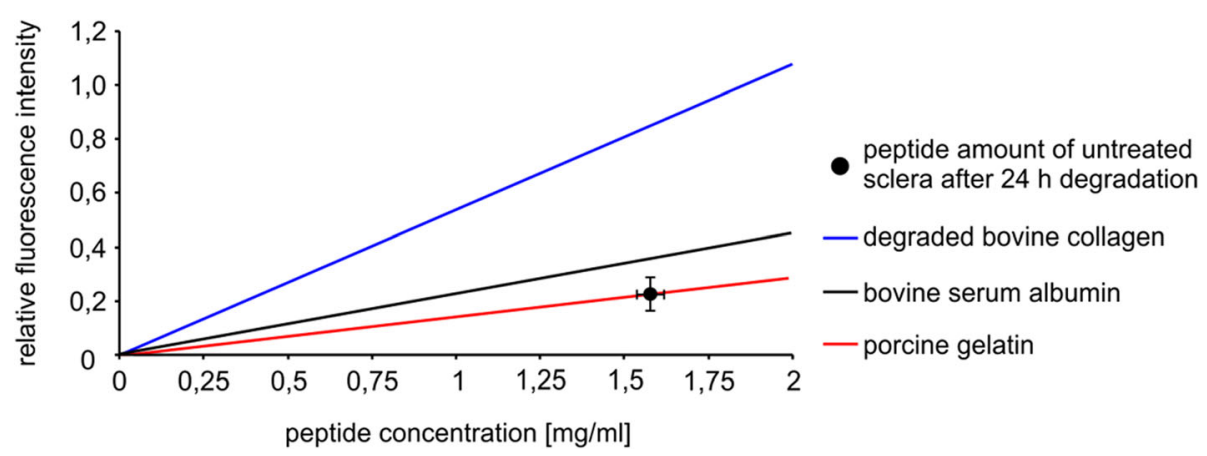

Fig. 3 Comparison of different peptide standards for the calculation of scleral peptide degradation products. Collagenase I (MMP1) degraded bovine collagen (blue curve), bovine serum albumin (black curve) and porcine gelatin (red curve) were diluted, incubated with Fluoraldehyde oPhthaldialdehyde and checked for their fluorescence intensity. The standard curves (based on fluorescence values of each indicated peptide concentration) were compared to the fluorescence intensity of the supernatant of non-cross-linked rabbit scleras after the $24 \mathrm{~h}$-degradation by MMP1 (black dot). The peptide amount per $1 \mathrm{ml}$ supernatant from the non-cross-linked sclera after $24 \mathrm{~h}$ degradation by MMP1 was $1.58 \mathrm{mg} \pm$ 0.04 (horizontal SD) with a relative fluorescence intensity of $0.229 \pm 0.06$ (vertical SD), $n=15$. The means and its corresponding standard deviation are displayed. Porcine gelatin standard curve corresponds mostly to the real protein amount of the scleral patches 


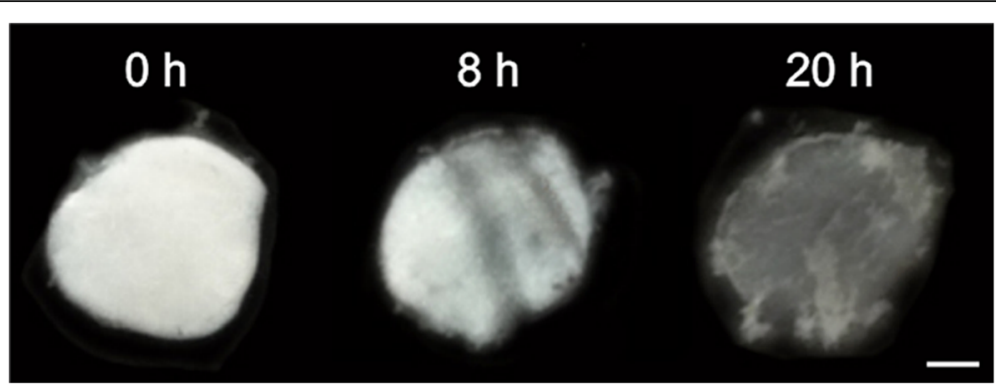

Fig. 4 Optical appearance of untreated (non-cross-linked) rabbit scleral patches after 0,8 and $20 \mathrm{~h} \mathrm{MMP1-degradation} \mathrm{(after} 24 \mathrm{~h}$ barely visible). No remarkable decrease of scleral patch diameter could be observed. The tissue became transparent and the surface became rough. Small tissue/ protein clots are dissociated from the patch and finally, a translucent tissue network remained in the incubation solution at $24 \mathrm{~h}$. Scale bar: $2 \mathrm{~mm}$

MMP1 degradation of untreated (non-cross-linked) sclera In a separate series of experiments we elucidate the time dependence of the enzymatic digestion of the untreated control scleral patches. The peptide amount in the supernatant after $24 \mathrm{~h}$ degradation of untreated sclera patches was set $100 \%$ as the control values to calculate the degradation degree after 1,4 and $8 \mathrm{~h}$. After $1 \mathrm{~h}$ incubation with MMP1 $10.9 \% \pm 4.9$ of the peptide compared to the untreated control sclera was detected in the supernatant. $44.2 \% \pm 8.5$ were measured at $4 \mathrm{~h}$ and at $8 \mathrm{~h}$ $73 \% \pm 9.2$ of the control peptide could be detected (mean of all controls, $n=15$ ). These values indicate a nearly linear digestion process up to $7 \mathrm{~h}$ and after $24 \mathrm{~h}$ most of the control patches were completely degraded (data calculation not shown). Despite a linear enzymatic digestion up to $7 \mathrm{~h}$ we decide to measure all above mentioned time points of each experimental approach to ensure a measurable amount of digested protein in all supernatant samples (especially, in experiments with strong inhibition of the digestion). All internal control values of the following experiments associated with various crosslinking methods are in consistency with this separate series of control measurements to establish the methodology (compare internal controls in Figs. 5, 6 and 7).

\section{MMP1 degradation after cross-linking with glutaraldehyde and paraformaldehyde}

Scleral patches were treated with glutaraldehyde (GA) or paraformaldehyde (PFA) for 1 or $5 \mathrm{~min}$ to evaluate the resulting resistance to enzymatic degradation by MMP1. Both cross-linking chemicals ("fixative agents" for biological material) significantly reduced the degradation of scleral tissue by MMP1 (Fig. 5). After $24 \mathrm{~h}$ only approximately $7 \%$ of the fixed patches were enzymatically

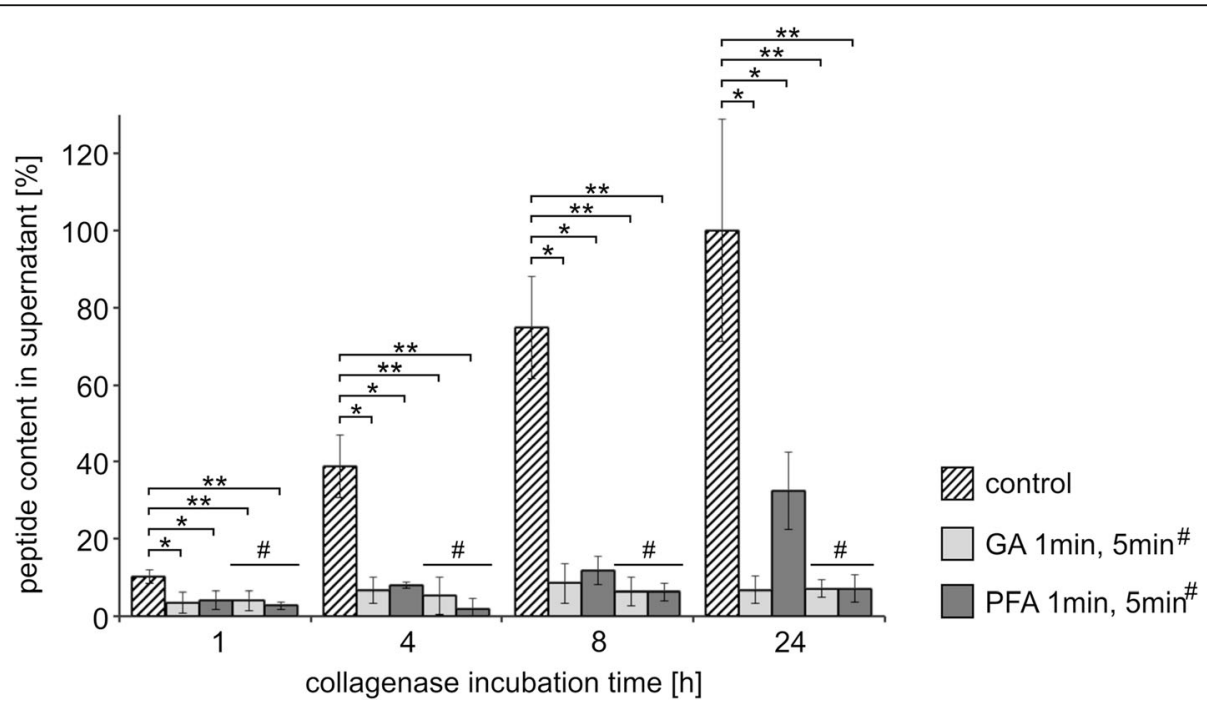

Fig. 5 Resistance of rabbit sclera to MMP1-degradation after cross-linking with glutaraldehyde (GA) and paraformaldehyde (PFA). Scleral patches were incubated ("fixed") for 1 or 5 min (\# indicates the 5 min values in the diagram) in GA and PFA. The amount of peptide in the supernatant was calculated as percentage of the degradation products of the untreated (non-cross-linked) control value after $24 \mathrm{~h}$ (each $24 \mathrm{~h}$ value of the corresponding internal control patch was set 100\%). GA and PFA 1 min $n=3$; GA and PFA 5 min and all non-crosslinked controls $n=5$. Means and standard deviations are presented. The statistical analysis was performed with the Mann-Whitney U-Test (unpaired, two tailed), $p^{*}<0.05, p^{* *}<0.01$ 


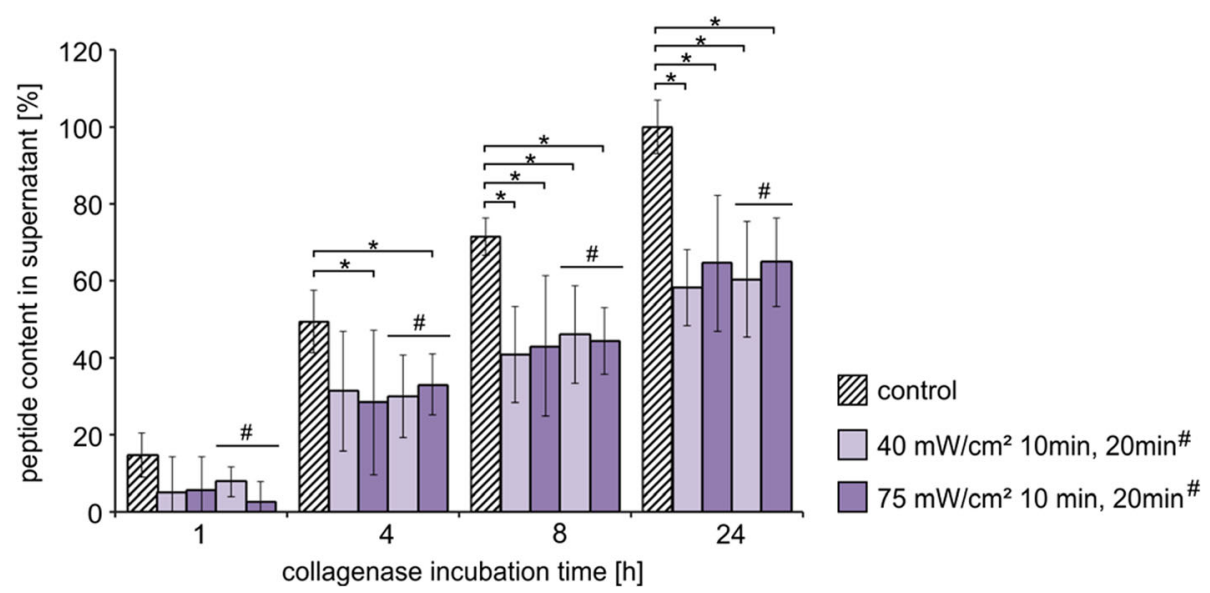

Fig. 6 Resistance of rabbit sclera to MMP1-degradation after cross-linking with riboflavin and UV-A-light with different light intensities (0.5\% riboflavin combined with 40 or $75 \mathrm{~mW} / \mathrm{cm}^{2}$ ) and different light exposure times (10 or 20 min (\# indicate the 20 min time in the diagram)). The amount of peptide in the supernatant was calculated as percentage of the degradation products of the untreated (non-cross-linked) control value after $24 \mathrm{~h}$ (each $24 \mathrm{~h}$ value of the corresponding internal control patch was set 100\%). Means $(n=4)$ and standard deviation are presented. The statistical analysis was performed with the Mann-Whitney U-Test (unpaired, two tailed), $p^{*}<0.05$

degraded (GA, 1 min to $6.8 \% \pm 3.4 ; \mathrm{GA}, 5 \mathrm{~min}$ to $7 \% \pm 2.3$ and PFA, 5 min to $7 \% \pm 3.5$ ). The incubation for $1 \mathrm{~min}$ in PFA reduced the degradation to $32.6 \% \pm$ 10 after $24 \mathrm{~h}$. Therefore, GA is a stronger cross-linker and inhibitor of the enzymatic digestion than PFA after very short-time $(1 \mathrm{~min})$ incubation. After $5 \mathrm{~min}$ incubation (fixation) with GA we could not detect any remarkably differences of the enzymatic degrading potency. The enzymatic degradation was more reduced after $5 \mathrm{~min}$ incubation with paraformaldehyde compared to $1 \mathrm{~min}$ incubation (Fig. 5).

\section{MMP1 degradation after cross-linking with riboflavin and UV-A}

The treatment with riboflavin and UV-A-light significantly reduced the enzymatic degradation of scleral tissue in comparison to the untreated control (Fig. 6). At $24 \mathrm{~h} 62 \% \pm 12.7$ of the sclera was degraded after crosslinking with riboflavin and UV-A-light compared to control. Neither clear difference of inhibition could be detected using higher light intensities nor higher light exposure times $\left(40 \mathrm{~mW} / \mathrm{cm}^{2} / 10 \mathrm{~min}\right.$ to $58.1 \% \pm 9.9$ vs. $40 \mathrm{~mW} / \mathrm{cm}^{2} / 20 \mathrm{~min}$ to $60.4 \% \pm 17.8$ and $75 \mathrm{~mW} / \mathrm{cm}^{2} / 10$

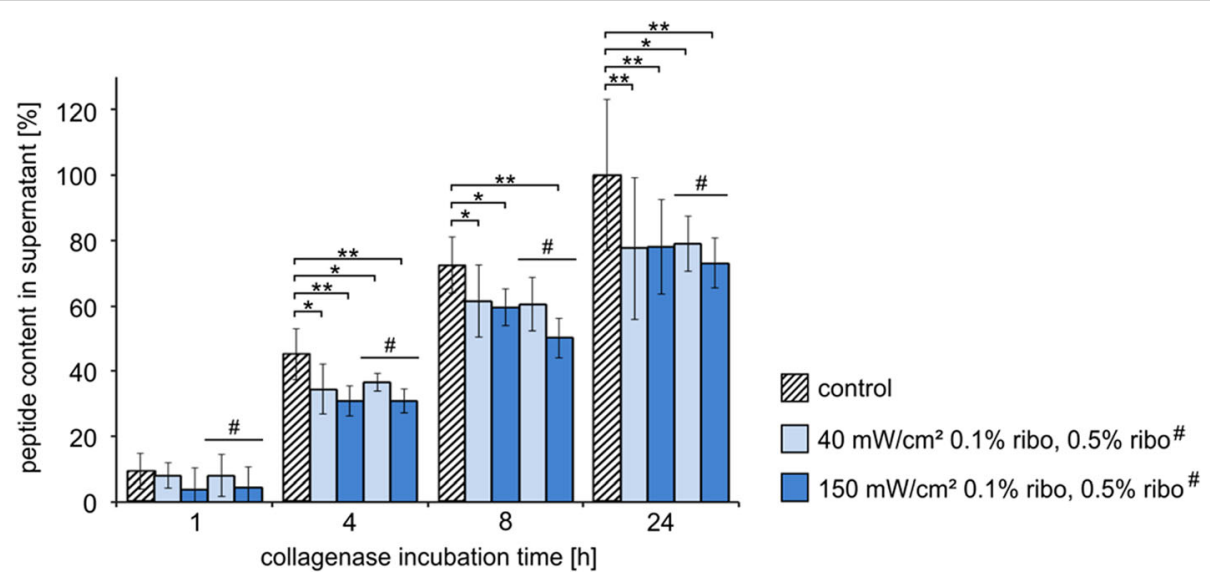

Fig. 7 Resistance of rabbit sclera to MMP1-degradation after cross-linking with riboflavin and blue light of different light intensities (20 min exposure time with 40 or with $150 \mathrm{~mW} / \mathrm{cm}^{2}$ ) and treatment with different riboflavin concentrations $(0.1 \%$ or $0.5 \%$ (\# indicate the treatment with $5 \%$ riboflavin in the diagram). The amount of peptide in the supernatant was calculated as percentage of the degradation products of the untreated (non-cross-linked) control value after $24 \mathrm{~h}$ (each $24 \mathrm{~h}$ value of the corresponding internal control patch was set $100 \%)$. Means $(n=6)$ and the standard deviations are presented. The statistical analysis was performed with the Mann-Whitney U-Test (unpaired, two tailed), $p^{*}<0.05, p^{* *}<0.01$ 
$\min$ to $64.5 \% \pm 14.9$ vs. $75 \mathrm{~mW} / \mathrm{cm}^{2} / 20 \mathrm{~min}$ to $64.9 \% \pm$ 11.5). The treatment of the scleral tissue with riboflavin $(0.5 \%)$ only without an UV-A or blue light irradiation did not result in a decelerated enzymatic sclera degradation (data not shown).

\section{MMP1 degradation after cross-linking with riboflavin and blue light}

Cross-linking with riboflavin and blue light reduced the scleral degradation to $76.9 \% \pm 13.5$ after $24 \mathrm{~h}$ (Fig. 7). Neither clear difference of inhibition could be detected using higher light intensities nor a higher riboflavin concentration $\left(40 \mathrm{~mW} / \mathrm{cm}^{2} / 0.1 \%\right.$ riboflavin to $77.7 \% \pm 14.6$ vs. $40 \mathrm{~mW} / \mathrm{cm}^{2} / 0.5 \%$ riboflavin to $79 \% \pm 21.7$ and 150 $\mathrm{mW} / \mathrm{cm}^{2} / 0.1 \%$ riboflavin to $78 \% \pm 7.7$ vs. $150 \mathrm{~mW} / \mathrm{cm}^{2} /$ $0.5 \%$ riboflavin to $73.1 \% \pm 8.5$ ).

\section{Comparison of glutaraldehyde, paraformaldehyde, riboflavin/UV-A-light and riboflavin/blue light}

The direct comparison of differently cross-linked sclera (Fig. 8) shows that the chemical cross-linking with glutaraldehyde and paraformaldehyde is most effective with a significantly higher reduction of enzymatic degradation down to $7 \% \pm 2.8$ compared to the cross-linking with riboflavin and UV-A or blue light.

The resistance to enzymatic digestion seems to be stronger in scleral tissue treated with riboflavin and UVA-light compared to a treatment with riboflavin and blue light. The treatment of scleral tissue with riboflavin and UV-A-light reduced the enzymatic degradation to $62 \% \pm 12.7$ whereas the treatment with riboflavin and blue light caused a reduction to $76.9 \% \pm 13.5$ (24h values). However, the differences were not statistically significant probably caused by the restricted numbers of experiments combined with the biological variation.

In this study the treatment with riboflavin and blue light has the smallest impact as cross-linker and shows the lowest effect on inhibition of the enzymatic degradation. Neither changes of riboflavin concentration nor changes of the light intensities of each wavelength effects the outcome significantly. Obviously, the grade of inhibition of the enzymatic degradation at every time point (1, 4, 8 and $24 \mathrm{~h})$ in each of the examined cross-linking approaches is similar.

\section{Discussion}

Our study revealed for the first time, that all examined cross-linking approaches increase the resistance to enzymatic digestion of rabbit scleral tissue, at which the chemical cross-linkers were the most effective. Therefore, cross-linking methods might be in future a promising clinical approach to treat ocular inflammatory or melting diseases of the eye.

Spoerl, Wollensak and Seiler evaluated the enzymatic resistance of porcine corneas by measuring the decreasing diameter after incubation with collagen degrading

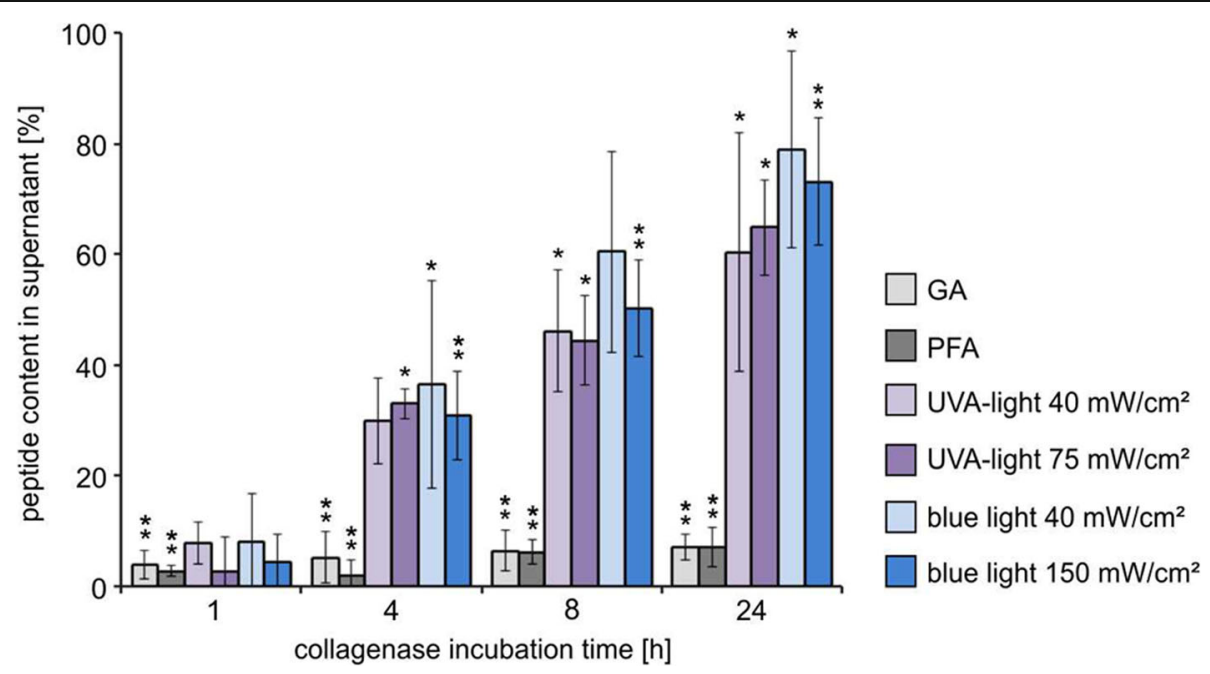

Fig. 8 Comparison of rabbit scleral resistance to MMP1 after cross-linking with glutaraldehyde (GA, 1\%, 5 min), paraformaldehyde (PFA, 4\%, 5 $\mathrm{min}$ ), riboflavin/UV-A-light (0.5\% riboflavin; 40 and $75 \mathrm{~mW} / \mathrm{cm}^{2}, 20 \mathrm{~min}$ irradiation time) and riboflavin/blue light (0.5\% riboflavin; $40 \mathrm{and} 150 \mathrm{~mW} /$ $\mathrm{cm}^{2}, 20$ min irradiation time) of different light intensities. The amount of peptide in the supernatant was calculated as percentage of the degradation products of the untreated (non-cross-linked) control value after $24 \mathrm{~h}$ (each $24 \mathrm{~h}$ value of the corresponding internal control patch was set 100\%). Each of the cross-linking methods reduced the degradation of rabbit sclera by MMP1. Cross-linking with the chemical cross-linkers GA and PFA reduced the degradation to $7 \%$ at $24 \mathrm{~h}(n=5)$. The treatment with riboflavin/UV-A-light reduced the enzymatic degradation of rabbit sclera to $62 \%$ at $24 \mathrm{~h}(n=4)$. No significant differences in resistance to enzymatic degradation were detected using higher light intensities. After riboflavin/blue light cross-linking the enzymatic degradation of rabbit sclera was reduced to $77 \%$ at $24 \mathrm{~h}(n=6)$. No differences in resistance to enzymatic degradation were detected using higher light intensities. Means and standard deviation are presented. The statistical analysis was performed with the Mann-Whitney U-Test to the corresponding control (unpaired, two tailed), $p^{*}<0.05, p^{* *}<0.01$ 
enzymes [12]. Contrary, in our experiments the macroscopic appearance of the scleral patch samples (as shown in Fig. 3) did not enable such quantification of degradation by collagenase 1 (MMP1). We did not observe a remarkable decrease of the scleral patch diameter instead of other changes as sign of tissue degradation (e.g. tissue becomes transparent).

This might be due to a slightly different biochemical composition of the rabbit scleral tissue compared to the porcine cornea and the specificity of the used collagenase I enzyme. The extracellular matrix of the sclera is composed of fibrillary proteins such as collagen and elastin and additionally of amorphous ground substance such as proteoglycans and glycoproteins. Type I, III, V and VI collagen are present in the sclera, although biochemical analyses have shown that collagen type I predominates the composition while type III represent less than $5 \%$ additionally with a small amount of other protein species [23]. MMP1 is specific to collagen I, II and III (and some other collagens), but cleaves also gelatin, some other extracellular matrix proteins and serum proteins. However, it does not cleave elastin [24]. This may explain a residual network of non-degraded elastin, proteoglycans and glycoproteins of the scleral remaining after $24 \mathrm{~h}$ incubation with MMP1. Thus, measuring of patch diameters was not an appropriate method for studying the scleral resistance to enzymatic degradation.

For that reason, we decided to measure the scleral collagen degradation products in the supernatant with a sensitive peptide detection method. Since 1971 the reagent o-Phthaldialdehyde (OPA) + 2-mercaptoethanol is used to detect even small amounts of amino acids, peptides and proteins. Its high sensitivity in the picomole range is due to its reaction with primary amines yielding highly fluorescent isoindole derivatives $[25,26]$. GO et al. [27] showed that OPA could detect cleaved collagen (enzymatically degraded collagen, detection of > $5 \mu \mathrm{g}$ ) with a linear relationship between collagen amount and fluorescence emission. The exposure of the $\mathrm{N}$ termini resulting from collagen breakage leads to an increase of the OPA fluorescence [27]. The exposure of collagen to bacterial collagenase increased the fluorescence intensity in a dependence of increasing enzyme amounts. In comparison to mammalian collagenase, the bacterial collagenase cleaves collagen in small peptides and not only to $3 / 4$ and $1 / 4$-fractions [28]. That increases the sensitivity. Consequently, OPA is a suitable and simple realizable method to detect bacterial MMP1degradation products of collagen.

In future, methods to change the resistance to enzymatic degradation should also be examined with other collagen cleaving enzymes like gelatinase A, stromelysin and gelatinase $\mathrm{B}$ which are expressed by scleral fibroblasts [29]. These results might provide an indication of several types of cross-links generated by different methods and their cross-linking strength.

\section{Cross-linking by GA and PFA}

In our study, we found that all cross-linking methods reduced the enzymatic degradation by MMP1 of rabbit scleral tissue.

The exposure of proteins to various cross-linkers is accompanied by generation of inter- and intramolecular covalent bonds [30, 31]. Cross-linking increases the resistance of collagenous tissue to enzymatic degradation by collagenase I because the tertiary structure of the protein is changed and with that, the enzymatic access to specific cleavage sites is hampered [13, 32].

In this study, the chemicals glutaraldehyde (GA) and paraformaldehyde (PFA) are the strongest cross-linkers with a nearly complete inhibition of the enzymatic degradation. GA and PFA form bonds between their aldehyde groups and adjacent macromolecules and remain as molecule in the tissue [33-35]. With a 5 min incubation/fixation time, GA and PFA similarly reduced the enzymatic degradation of scleral tissue. This result confirms earlier studies, which showed a similar degree of bacterial collagenase I degradation of collagen after a glutaraldehyde or formaldehyde treatment [36, 37]. However, the chemical cross-linking mechanism of both is different [38] and fixation by formaldehyde (compared to glutaraldehyde) is a slower and generates cross-links with time $[39,40]$. This might explain our result, that one-minute incubation with PFA reduced the enzymatic degradation only to $33 \%$.

\section{Cross-linking by riboflavin and UV-A or blue light}

In contrast to chemical cross-linkers, the bonding of collagen fibrils by a physical cross-linking is mediated by reactive oxygen species and free radicals. These have a single unpaired electron, which makes them highly reactive against surrounding substances [41], and thereby, can connect amino residues of adjacent collagen molecules. No additional chemical groups are incorporated in the covalent cross-links between amino acids of the collagen molecules in comparison to chemical cross-linkers as glutaraldehyde or formaldehyde [42].

The physical cross-linking with the photosensitizer riboflavin and irradiation with light of different wavelengths reduced the MMP1-degradation rate of scleral tissue to $62 \%$ with UV-A-light and $77 \%$ with blue light. This difference might be explainable by the shorter wavelength of UV-A-light compared to blue light. Shortwavelength light possesses more photon energy and might lead to a stronger production of reactive oxygen species and free radicals when applied to excitable molecules [43, 44]. Furthermore, UVA light irradiation of riboflavin induces similar reactive oxygen species, 
radicals and chemical decay products as blue light but in other proportions [45]. Thus, the application of UV-Alight and riboflavin lead to other amounts of reactive oxygen species and free radicals and therefore, to an increased total amount of cross-links in scleral tissue compared to blue light of comparable light intensity (e.g. $40 \mathrm{~mW} / \mathrm{cm}^{2}$ ). Consequently, the enzymatic digestion is more affected by a riboflavin/UV-A-light application than after riboflavin/blue light application. This phenomenon was also observed comparing different cross-linking technics of their ability to increase the biomechanical stiffness of porcine corneas. According to Spoerl \& Seiler, Karnovsky's solution and glutaraldehyde are the most effective cross-linkers followed by riboflavin/UV-A-light, methylglyoxal, glyceraldehyde, riboflavin/blue light and ribose. The weakest cross-linkers are glucose and short-wave UV-A-light $(265 \mathrm{~nm})$ [11]. The usage of riboflavin with UV-A-light led to a two-fold higher increase in corneal stiffness compared to the application of riboflavin and blue light at same exposure times and light intensities [11].

No significant differences in resistance to enzymatic degeneration could be detected when comparing different light intensities, light exposure times and riboflavin concentrations (Figs. 6, 7 and 8). Spoerl et al. could identify clear differences in enzymatic resistance after usage of 1 and $2 \mathrm{~mW} / \mathrm{cm}^{2} \mathrm{UV}$-A-light in porcine corneas at which a higher light intensity resulted in a stronger resistance [12]. As well as longer irradiation time (30 and $45 \mathrm{~min}$ ) with UV-A-light led to a stronger increase of the biomechanical rigidity of porcine corneas [11]. In our studies, the differences might be too small to be distinguished with the performed method or the applied light intensities (40 and $75 \mathrm{~mW} / \mathrm{cm}^{2}$ UV-A-light; 40 and $150 \mathrm{~mW} / \mathrm{cm}^{2}$ blue light) were too high so that the maximal cross-link amount was already achieved. That means, we were in a saturation range with the lowest intensity and irradiation time applied. To elucidate the detailed kinetic of cross-linking an extended series of experiments must be performed in future.

Since riboflavin is not only the provider of reactive oxygen species but also a scavenger itself, a balance between reactive oxygen species generation and elimination is reached at higher concentrations. Therefore, an increase in riboflavin concentration does not inevitably lead to a higher yield of reactive oxygen species [46]. This might explain why we could not detect any differences in enzymatic resistance of scleral tissue treated with 0.1 and $0.5 \%$ riboflavin and blue light. In future, variations of concentration, light intensities and irradiation times should be probed to characterize parameters for the most effective and gentle application in humans to strengthen the sclera in melting diseases such as scleritis or in progressive myopia.

\section{Conclusion}

Scleral tissue degradation occurs in ocular inflammatory or melting diseases of the eye. Our study revealed for the first time, that cross-linking treatments with glutaraldehyde, paraformaldehyde or riboflavin application combined with UV-A-light or blue light irradiation inhibit the enzymatic degradation of scleral tissue. Although, the chemical cross-linkers were the most effective in inhibiting enzymatic degradation the clinically established procedures of riboflavin application combined with UV-A-light or blue light are the promising approaches for a future clinical treatment.

\section{Abbreviations \\ GA: Glutaraldehyde; MMP1: Matrix-Metallo-Proteinase 1 (i.e. collagenase I); OPA: Ortho-Phthaldialdehyde; PBS: Phosphate buffered saline; \\ PFA: Paraformaldehyde; SXL: Scleral cross-linking; UV-A-light: Ultraviolet light A}

\section{Acknowledgments}

We thank Prof. Mrochen and Dr. Iseli for providing the UV-A irradiation device. We acknowledge support from Leipzig University for Open Access Publishing.

\section{Authors' contributions}

KK, CF, MF and NK designed the study. KK, CF and NK performed the experiments, collected the data and were involved in the analysis. RB, FGR and MF analyzed the data and designed the data presentation. MF and FGR wrote the first draft of the manuscript. RB reviewed and revised the manuscript. MF and FGR produced the final version. All authors have read and approved publication of the final manuscript.

\section{Funding}

The work presented was kindly supported by funding from the German Federal Ministry of Education and Research (BMBF, 1315883 to NK, MF), from the Deutsche Forschungsgemeinschaft (FR 1825/1-1 to MF) and from the Government of Saxony, Germany (Ministry for Science and Art and Sächsische Aufbau-Bank) to MF (SAB Project No. 100175 031, University Project No. 5081-7008). All funders were exclusively supporting research without any commercial interests. Open Access funding enabled and organized by Projekt DEAL.

\section{Availability of data and materials}

The datasets analyzed in this study are available from the corresponding author (Mike Francke, mike.francke@medizin.uni-leipzig.de) upon reasonable request.

\section{Ethics approval and consent to participate}

The authors have considered all ethical aspects of the study and followed the guidelines of the Helsinki Declaration and all experiments were done in accordance with the European Communities Council Directive 86/609/EEC and the ARVO Statement for the Use of Animals in Ophthalmic and Vision Research. Experiments were approved by the local authorities (Faculty of Medicine of the University of Leipzig). We did not perform any animal experiments or obtained clinical data from probands.

\section{Consent for publication}

NA

\section{Competing interests}

The authors declare that they have no competing interests.

\section{Author details}

${ }^{1}$ Paul-Flechsig-Institute of Brain Research, Leipzig University, Liebigstraße 19, 04103 Leipzig, Germany. Fachbereich SciTec, Ernst-Abbe-Hochschule Jena, University of Applied Sciences, Carl-Zeiß-Promenade 2, 07745 Jena, Germany. ${ }^{3}$ Institute for Medical Informatics, Statistics and Epidemiology (IMISE), Leipzig University, Härtelstraße 16-18, 04107 Leipzig, Germany. 
Received: 11 March 2020 Accepted: 30 November 2020

Published online: 14 December 2020

\section{References}

1. Wollensak G, lomdina E, Dittert D-D, Salamatina O, Stoltenburg G. Crosslinking of scleral collagen in the rabbit using riboflavin and UVA. Acta Ophthalmol Scand. 2005:83:477-82.

2. Wollensak G, Spoerl E. Collagen crosslinking of human and porcine sclera. J Cataract Refract Surg. 2004;30:689-95.

3. Celorio JM, Pruett RC. Prevalence of lattice degeneration and its relation to axial length in severe myopia. Am J Ophthalmol. 1991;111:20-3.

4. Curtin BJ, Karlin DB. Axial length measurements and fundus changes of the myopic eye. Am J Ophthalmol. 1971;71:42-53.

5. Tano. Pathologic myopia: where are we now? 2002. https://doi.org/10.1016/ S0002-9394(02)01883-4 .

6. Dotan A, Kremer I, Livnat T, Zigler A, Weinberger D, Bourla D. Scleral crosslinking using riboflavin and ultraviolet-a radiation for prevention of progressive myopia in a rabbit model. Exp Eye Res. 2014;127:190-5.

7. Iseli HP, Korber N, Koch C, Karl A, Penk A, Huster D, Reichenbach A, Wiedemann P, Francke M. Scleral cross-linking by riboflavin and blue light application in young rabbits: damage threshold and eye growth inhibition. Graefes Arch Clin Exp Ophthalmol. 2016;254:109-22.

8. Wollensak $\mathrm{G}$, lomdina E. Crosslinking of scleral collagen in the rabbit using glyceraldehyde. J Cataract Refract Surg. 2008;34:651-6.

9. Schuldt C, Karl A, Körber N, Koch C, Liu Q, Fritsch AW, Reichenbach A, Wiedemann P, Käs JA, Francke M, Iseli HP. Dose-dependent collagen crosslinking of rabbit scleral tissue by blue light and riboflavin treatment probed by dynamic shear rheology. Acta Ophthalmol. 2015;93(5):e328-36. https:// doi.org/10.1111/aos.12621. Epub 2014 Dec 16.

10. Medina A, Greene PR. Progressive Myopia and Lid Suture Myopia are Explained by the Same Feedback Process: a Mathematical Model of Myopia. J Nat Sci. 2015;1(6):e121.

11. Spoerl E, Seiler T. Techniques for stiffening the cornea. J Refract Surg. 1999; 15:711-3.

12. Spoerl E, Wollensak G, Seiler T. Increased resistance of crosslinked cornea against enzymatic digestion. Curr Eye Res. 2004;29:35-40.

13. Berman. Collagenase inhibitors: rationale for their use in treating corneal ulceration. Int Ophthalmol Clin. 1975;15:49-66.

14. Rehany U, Lahav M, Shoshan S. Collagenolytic activity in keratoconus. Ann Ophthalmol. 1982;14:751-4

15. Hall NF, Gale CR, Ye S, Martyn CN. Myopia and polymorphisms in genes for matrix metalloproteinases. Invest Ophthalmol Vis Sci. 2009;50:2632-6.

16. Nakanishi H, Hayashi H, Yamada R, Yamashiro K, Nakata I, Shimada N, OhnoMatsui K, Mochizuki M, Ozaki M, Yoshitake S, Kuriyama S, Saito M, lida T, Matsuo K, Matsuda F, Yoshimura N. Single-nucleotide polymorphisms in the promoter region of matrix metalloproteinase-1, -2 , and -3 in Japanese with high myopia. Invest Ophthalmol Vis Sci. 2010;51:4432-6.

17. Wojciechowski R, Yee SS, Simpson CL, Bailey-Wilson JE, Stambolian D. Matrix metalloproteinases and educational attainment in refractive error: evidence of gene-environment interactions in the age-related eye disease study. Ophthalmology. 2013;120:298-305.

18. McBrien NA, Gentle A. Role of the sclera in the development and pathological complications of myopia. Prog Retin Eye Res. 2003;22:307-38.

19. McBrien NA, Lawlor P, Gentle A. Scleral remodeling during the development of and recovery from axial myopia in the tree shrew. Invest Ophthalmol Vis Sci. 2000;41:3713-9.

20. Guggenheim JA, McBrien NA. Form-deprivation myopia induces activation of scleral matrix metalloproteinase-2 in tree shrew. Invest Ophthalmol Vis Sci. 1996:37:1380-95.

21. Jones BE, Thompson EW, Hodos W, Waldbillig RJ, Chader GJ. Scleral matrix metalloproteinases, serine proteinase activity and hydrational capacity are increased in myopia induced by retinal image degradation. Exp Eye Res. 1996:63:369-81.

22. Rada JA, Perry CA, Slover ML, Achen VR. Gelatinase A and TIMP-2 expression in the fibrous sclera of myopic and recovering chick eyes. Invest Ophthalmol Vis Sci. 1999:40:3091-9.

23. Watson PG, Young RD. Scleral structure, organisation and disease. A review. Exp Eye Res. 2004;78:609-23.

24. Nagase H. Substrate specificity of MMPs. In: Clendeninn NJ, Appelt K, editors. Matrix metalloproteinase inhibitors in cancer therapy. Cancer drug discovery and development. Totowa: Humana Press; 2001.
25. Roth M. Fluorescence reaction for amino acids. Anal Chem. 1971;43:880-2

26. Benson JR, Hare PE. O-phthalaldehyde: fluorogenic detection of primary amines in the picomole range. Comparison with fluorescamine and ninhydrin. Proc Natl Acad Sci U S A. 1975;72:619-22.

27. Go K, Horikawa Y, Garcia R, Villarreal FJ. Fluorescent method for detection of cleaved collagens using O-phthaldialdehyde (OPA). J Biochem Biophys Methods. 2008;70:878-82.

28. Mallya SK, Mookhtiar KA, van Wart HE. Kinetics of hydrolysis of type I, II, and III collagens by the class I and II Clostridium histolyticum collagenases. J Protein Chem. 1992;11:99-107.

29. Rada JAS, Shelton S, Norton TT. The sclera and myopia. Exp Eye Res. 2006; 82:185-200.

30. Balasubramanian D, Kanwar R. Molecular pathology of dityrosine cross-links in proteins: structural and functional analysis of four proteins. Mol Cell Biochem. 2002;234-235:27-38.

31. Kato Y, Uchida K, Kawakishi S. Aggregation of collagen exposed to UVA in the presence of riboflavin: a plausible role of tyrosine modification. Photochem Photobiol. 1994;59:343-9.

32. Weadock KS, Miller EJ, Keuffel EL, Dunn MG. Effect of physical crosslinking methods on collagen-fiber durability in proteolytic solutions. J Biomed Mater Res. 1996;32:221-6.

33. Speer DP, Chvapil M, Eskelson CD, Ulreich J. Biological effects of residual glutaraldehyde in glutaraldehyde-tanned collagen biomaterials. J Biomed Mater Res. 1980;14:753-64.

34. Cheung DT, Nimni ME. Mechanism of crosslinking of proteins by glutaraldehyde II. Reaction with monomeric and polymeric collagen. Connect Tissue Res. 1982;10:201-16.

35. Thavarajah R, Mudimbaimannar VK, Elizabeth J, Rao UK, Ranganathan K. Chemical and physical basics of routine formaldehyde fixation. J Oral Maxillofac Pathol. 2012;16:400-5.

36. Harris ED, Farrell ME. Resistance to collagenase: a characteristic of collagen fibrils cross-linked by formaldehyde. Biochim Biophys Acta. 1972;278:133-41.

37. Levy RJ, Schoen FJ, Sherman FS, Nichols J, Hawley MA, Lund SA. Calcification of subcutaneously implanted type I collagen sponges. Effects of formaldehyde and glutaraldehyde pretreatments. Am J Pathol. 1986;122: $71-82$.

38. Paul RG, Bailey AJ. Chemical stabilisation of collagen as a biomimetic. ScientificWorldJournal. 2003;3:138-55.

39. Helander KG. Kinetic studies of formaldehyde binding in tissue. Biotech Histochem. 1994;69:177-9.

40. Rong S, Wang C, Han B, Feng P, Lan W, Gao Z, Li X, Chen W. Iontophoresisassisted accelerated riboflavin/ultraviolet A scleral cross-linking: a potential treatment for pathologic myopia. Exp Eye Res. 2017;162:37-47.

41. Turrens JF. Superoxide production by the mitochondrial respiratory chain. Biosci Rep. 1997;17:3-8.

42. Stadtman ER, Levine RL. Chemical modification of proteins by reactive oxygen species. In: Dalle-Donne I, Scaloni A, Butterfield DA, editors. Redox proteomics: from protein modifications to cellular dysfunction and diseases. Hoboken: Wiley; 2006. p. 1-23.

43. Rozanowska M, Jarvis-Evans J, Korytowski W, Boulton ME, Burke JM, Sarna T. Blue light-induced reactivity of retinal age pigment. In vitro generation of oxygen-reactive species. J Biol Chem. 1995;270:18825-30.

44. Rozanowska M, Wessels J, Boulton M, Burke JM, Rodgers MA, Truscott TG, Sarna T. Blue light-induced singlet oxygen generation by retinal lipofuscin in non-polar media. Free Radic Biol Med. 1998;24:1107-12.

45. Omata Y, Lewis JB, Rotenberg S, Lockwood PE, Messer RLW, Noda M, Hsu SD, Sano H, Wataha JC. Intra- and extracellular reactive oxygen species generated by blue light. J Biomed Mater Res A. 2006;77:470-7.

46. Huang $R$, Choe $E$, Min DB. Kinetics for singlet oxygen formation by riboflavin photosensitization and the reaction between riboflavin and singlet oxygen. J Food Sci. 2004;69:C726-32.

\section{Publisher's Note}

Springer Nature remains neutral with regard to jurisdictional claims in published maps and institutional affiliations. 